Cómo citar este trabajo: Yubero, C., \& García Hernández, M. (2019). El turismo en el medio rural en España desde el enfoque de la transferencia de políticas públicas. Boletín de la Asociación de Geografía Española, 81, 2766, 1-34. http://dx.doi.org/10.21138/bage.2766

\title{
El turismo en el medio rural en España desde el enfoque de la transferencia de políticas públicas
}

Tourism in Spanish rural areas from a policy transfer perspective

\author{
Claudia Yubero \\ claudiayubero@ucm.es

\section{María García Hernández} \\ mgarciah@ghis.ucm.es \\ Departamento de Geografía \\ Universidad Complutense de Madrid (España)
}

\section{Resumen}

Cuando se cumplen casi tres décadas desde el arranque del turismo rural en España, se percibe un déficit de atención a la circulación de los instrumentos y modelos que han marcado su desarrollo. Sin embargo, los procesos de recomposición del medio rural europeo están profundamente afectados por flujos globales de políticas públicas en las que el turismo ocupa un lugar predominante. Por ello esta investigación propone una lectura del desarrollo del turismo en el medio rural a través del marco de la transferencia de los programas LEADER y Planes en Destino, instrumentos de la Política Europea de Desarrollo Rural y de la Política Turística nacional, respectivamente. Adoptando el marco analítico propuesto por Dolowitz y Marsh (2000) se hace recapitulación de la literatura que estudia la implantación de ambas políticas con el objetivo de sistematizar y caracterizar su transferencia. En particular, se aporta el estudio de su contenido desde una perspectiva evolutiva atendiendo a los modelos de turismo que se ponen en circulación. 
Palabras clave: turismo en el medio rural; transferencia de políticas públicas; LEADER; Planes turísticos en destino; circulación de modelos.

\begin{abstract}
When nearly three decades have passed since the start of rural tourism in Spain, the literature seems to have neglected the circulation of instruments and models that have marked its development. However, the process of recomposition of the European rural areas is deeply affected by global flows of public policies where tourism occupies a predominant place. Therefore, this research proposes a policy transfer perspective to understand the development of tourism in rural areas of Spain. It deals with two policy instruments: LEADER (European Policy for Rural Development) and Destiny Plans (National Tourism Policy). The literature on its implementation is articulated with the analytical framework proposed by Dolowitz and Marsh (2000) to offer a systematization and a characterization of its transfer. In particular, the study offers an analysis of the transferred content from an evolutionary perspective considering the tourism models that are put into circulation.
\end{abstract}

Key words: tourism in rural areas; policy transfer; LEADER; Destination Plans; model circulation.

\title{
1 Introducción
}

En treinta años de iniciativas públicas de turismo en el medio rural en España, se ha pasado de un número reducido de experiencias de desarrollo turístico a un verdadero crecimiento que no deja territorio (con mayor o menor grado de ruralidad) desprovisto de estas, ya sea en fases incipientes o consolidadas. En este contexto, ha sido recurrente en la literatura contemporánea poner de manifiesto las fallas de la aplicación de instrumentos públicos de fomento del turismo en la consecución de un modelo sostenible, hasta el punto de considerarlos "fracasados" (Cànoves, Villarino \& Herrera, 2006; McAreavey \& McDonagh, 2011; Sharpley \& Roberts, 2004). Contribuyen factores como un sistema de evaluación superficial (Bull, 1999; Tirado Ballesteros \& Hernández Hernández, 2017), una excesiva concentración de la inversión hacia los proyectos de apertura de alojamientos (Masot \& Alonso, 2017; Pitarch \& Amandís, 2014), la falta de planificación de su ubicación (Blancas, Guerrero Casas, \& Lozano Oyola, 2009; Sánchez, Sánchez, \& Rengifo, 2017), la insostenibilidad económica de las actuaciones (Vázquez Varela \& Martín Gil, 2011), y una ingenua confianza en que los recursos locales, sobre todo patrimoniales, pueden, por sí solos, generar un flujo turístico (Prats, 2011). Todas estas causas están en cierta medida relacionadas con el entendimiento del turismo como la "panacea del desarrollo rural".

Sin embargo, en un contexto de proliferación de iniciativas, se percibe en la literatura especializada un déficit de atención a la consideración sistematizada del proceso de difusión de modelos de turismo en el medio rural. Este déficit sorprende por la importancia que se le da a los mecanismos 
de intercambio de políticas públicas en términos de innovación y la rapidez a la que están sometidos en la actualidad. En este contexto, la corriente de estudios sobre las transferencias de políticas públicas tiene un gran potencial para facilitar algunas claves que permitan entender el fenómeno desde una perspectiva más amplia que englobe todas las escalas de decisión, circulación e implementación.

La corriente de estudios de transferencia de políticas públicas trata de comprender la puesta en marcha en un contexto político dado de soluciones de acción pública fabricadas en otros contextos políticos cuestionando los efectos de convergencia de ambos contextos. Existe un consenso en la literatura en determinar que, aunque no es un fenómeno nuevo, sí asistimos a un crecimiento sin precedentes debido a las dinámicas de la globalización y a la creciente integración de las economías políticas hacia el desarrollo del sistema capitalista neoliberal (Delpeuch, 2009; Dolowitz \& Marsh, 2000; Peck, 2011; Stone, 2017). Los avances de las tecnologías de la comunicación y el auge de las redes sociales han facilitado los intercambios de modelos y formas de proceder que facilitan la búsqueda de soluciones a problemas que se perciben comunes. El marco de las integraciones supranacionales, los mayoritariamente tratados por esta corriente, favorece procesos de transferencia de arriba abajo mediante acuerdos multilaterales y armonización reglamentaria. También se ha identificado la creciente horizontalidad de las transferencias de la mano de consultorías, ONGs, instituciones académicas y redes locales creadas y activadas bajo el paraguas de organismos internacionales como el FMI, el Banco Mundial o la Unión Europea (Peck \& Theodore, 2010).

El objetivo de esta investigación es ofrecer una lectura actualizada del fomento del turismo en el medio rural en clave de transferencias para ampliar los horizontes de análisis de este fenómeno. Al igual que se reconoce que los territorios rurales están influenciados por distintos modelos de desarrollo y no uno único que pueden complementarse o entrar en contradicción (GaldeanoGómez, Aznar-Sánchez \& Pérez-Mesa, 2011; Paül, 2013; Vázquez-Barquero \& Rodríguez-Cohard, 2016), se asume la hipótesis de que el turismo también se construye sobre la base de distintos instrumentos y distintos modelos de desarrollo.

Para ello se realiza, en el primer apartado, una revisión de los estudios de las transferencias incluyendo los importantes avances que se han realizado desde las ciencias políticas y, especialmente, la geografía urbana con un enfoque relacional (Peck, 2011; Temenos \& McCann, 2012). En el segundo apartado, se ofrece una sistematización de la transferencia de dos importantes instrumentos de reconocido peso en el desarrollo turístico del medio rural, LEADER y los Planes en Destino (Vázquez Varela \& Martín Gil, 2011), que se realiza bajo el marco analítico propuesto por Dolowitz y Marsh (2000). Se han seleccionado estos instrumentos por su enfoque territorial, suficiente longevidad y estructuración en el marco de políticas públicas definidas: la Política Europea de Desarrollo Rural y la Política Turística respectivamente. En particular, se aporta 
el estudio del contenido de esta transferencia desde una perspectiva evolutiva atendiendo a los modelos de turismo que se ponen en circulación. Por último, se concluye con una propuesta de investigación futura.

A nivel metodológico, el trabajo que sustenta los resultados recogidos en este texto se estructura en dos fases. En una primera fase, se realizó una revisión de la literatura sobre la implementación del turismo en el medio rural y su interpretación dentro del marco analítico de las transferencias de políticas públicas. Y en una segunda, se elaboró un análisis diacrónico del modelo transferido a partir de la documentación institucional y reglamentaria de la Unión Europea en el caso del instrumento LEADER y del Gobierno de España en el caso de los Planes en Destino.

Si bien es cierto que la reciente crisis económica y la decepción tras décadas de aprendizajes han desmitificado la imagen idealizada del turismo en el medio rural (Barrado Timón, 2014), también lo es que, con las actuales cifras de recuperación del mercado, se espera un nuevo auge de su desarrollo. En este contexto, urge una revisión de la transferencia de modelos del turismo en el medio rural para afrontar el interés renovado por ellos que se espera por parte de los territorios.

\section{La transferencia de políticas públicas en el panorama actual del policy making y los nuevos enfoques desde el espacio relacional}

\subsection{La transferencia de políticas públicas desde el enfoque ortodoxo}

La corriente de investigación sobre la transferencia de las políticas públicas (policy transfer studies) trata de comprender el proceso mediante el cual el conocimiento sobre políticas públicas, procedimientos administrativos, instituciones e ideas en un contexto político (pasado o presente) se usa para el desarrollo de políticas públicas, procedimientos administrativos, instituciones e ideas en otro contexto político (Dolowitz \& Marsh 2000: 5). En los trabajos que revisan esta corriente de estudios (Benson \& Jordan, 2011; Delpeuch, 2008; D. Dolowitz \& Marsh, 1996; Evans, 2004), se alude sistemáticamente a que se trata en realidad de una aproximación que surge en los años 90 y que renueva anteriores corrientes centradas en los mecanismos de difusión y de lesson-drawing, que se detenían en el estudio de las transferencias activadas por proximidad geográfica y acciones voluntarias de los decisores políticos.

A partir de los años 90, se contesta frontalmente la explicación positivista del fenómeno, según la cual la eficiencia sería la lógica de los intercambios de políticas públicas, llevado a cabo por decisores gubernamentales racionales que buscan, voluntariamente, las mejores soluciones para problemas globales compartidos. Dolowitz y Marsh (1996) comienzan a interesarse por los mecanismos de imposición, así como por los distintos grados de importación (desde la anteriormente sobrestimada copia literal hasta la mera inspiración). También se distingue un abanico mayor de actores involucrados como otros gobiernos no nacionales, consultores y ONG, y varias 
direcciones y escalas a las que se realizan las transferencias, especialmente subnacionales, comprometiendo así el "nacionalismo metodológico" que primaba en los estudios anteriores (Haas, 2015; Stone, 1999, 2004; Temenos \& McCann, 2012).

Todas estas aportaciones están recogidas en el marco analítico propuesto por Dolowitz y Marsh, realizado de forma inductiva a través de una revisión de la literatura (1996, 2000, 2012). Comúnmente aceptado, se articula en torno a seis preguntas consolidadas: ¿Quiénes son los actores implicados en las transferencias? ¿Qué es lo que se transfiere? ¿Por qué lo hacen? ¿Dónde nacen las soluciones? ¿Existen diferentes grados de transferencia? ¿Qué factores constriñen o facilitan la transferencia?

\subsection{Hacia un enfoque relacional de las transferencias}

Este marco analítico supone ciertos avances con respecto a la tradición racional-formalista en la que surgen estos estudios. Pero si bien esta evolución ha sido profusamente tratada (Benson \& Jordan, 2011; Delpeuch, 2008, 2009; Dussauge-Laguna, 2013; Stone, 2012), menos atención se le ha prestado en general, y en España en particular, a un nuevo salto teórico, propuesto a partir de 2010 por parte de algunos autores, fundamentalmente geógrafos anglosajones, que se reconoce como una prolongación que supera los límites de los policy transfer studies (McCann \& Ward, 2012).

Irrumpe así con fuerza una aproximación socio-constructivista que trata de revertir las bases ontológicas y epistemológicas de la corriente con postulados deuleuzianos reconociendo un proceso híbrido, móvil y localizado. Este impulso renovado ha sido denominado "enfoque heterodoxo" y etiquetado como "post-policy transfer approach" o "assemblages, mobilities and mutations approach" y, aunque su originalidad genera un fuerte debate en la academia que aquí no se tratará, bien podría considerarse que abre una nueva fase en los estudios de las transferencias que atiende con mayor profundidad cómo, por qué, dónde y con qué consecuencias circulan las políticas públicas y los modelos asociados (McCann \& Ward, 2013). En la raíz de su crítica se encuentra la idea de que ni las políticas públicas son paquetes cerrados, fácilmente definibles y replicables, ni los territorios son espacios discretos que emiten y reciben productos, resultando una relación dialéctica compleja de coproducción de ambos objetos: las políticas públicas movilizadas constituyen dinámicamente los lugares por los que viajan, a la vez que están incrustadas en ellos y son productos de regímenes y circuitos extralocales (Brenner, Peck \& Theodore, 2010).

Cuatro son los principales ejes de la crítica hacia los enfoques ortodoxos que subraya el enfoque del post-policy transfer (McCann \& Ward, 2013; Peck \& Theodore, 2010). Primero, los estudios deben aportar, además de la detección de todos los actores responsables, la consideración de su capacidad de apropiación. De esta manera, no se elude la dimensión social del policy-making 
como práctica interpersonal y basada en dinámicas subjetivas de comparación, aprendizaje, imitación, persuasión. Segundo, una simplificación excesiva de las escalas impide percibir que la movilidad de las políticas públicas es en realidad multi-direccional y una adhesión fija a las categorías de internacional/global y doméstico/local, o de fuera/dentro provoca la falsa presunción de que los modelos foráneos son construidos "fuera", cuando, en realidad, se construyen desde el lugar y en el preciso instante en que se describen, seleccionan y aplican. Tercero, la versión de los actores racionales que operan en espacios de policy-making relativamente desnudos es extremadamente limitante. El espacio del policy-making no es un mercado libre de soluciones y modelos listos para ser seleccionados voluntariamente sobre la base de claras prioridades, expertise e información, sino que está imbuido en lo que Massey denomina geometrías de poder (Albet \& Benach, 2012), plagado de canales preferidos, paradigmas o referenciales y centros de autoridad institucionalizados, que algunos autores ya han tratado en detalle (Ellison, 2017). Y cuarto, las transferencias no producen recepciones completas, sino que los objetos movilizados son mediados, interpretados, traducidos. De hecho, esto ha producido un repertorio de respuestas más complejo de lo que la práctica administrativa pretende (Peck \& Theodore, 2010).

En este marco, las transferencias de políticas públicas tienen implicaciones directas sobre la construcción de los modelos circulantes. Al transferirse un modelo o política, se está transfiriendo qué cuenta como "innovación", como "sostenible" (configurando así los denominados "policy fixes" (Temenos \& McCann, 2013)), como "buenas prácticas", e incluso qué no cuenta, al crearse también narrativas concretas sobre las políticas fracasadas (Gonzalez, 2011). En la transferencia hay, por tanto, selección de trazos del modelo que incluso se presentan como específicos a un lugar mediante un proceso de metanymic tagging, y por tanto auténticos y realizables. Sin embargo, se ha observado que puede existir una desconexión entre el modelo ideal y lo que realmente representa, pues son productos de las mencionadas traducciones (Peck \& Theodore, 2010).

La traducción, como microdinámica de los procesos de transferencia (Hadjinski, Pal, \& Walker, 2017) es uno de los elementos que ha suscitado creciente atención por parte de los últimos trabajos bajo este nuevo enfoque (Oliveira, 2018). La raíz del concepto proviene de la sociología francesa de la acción pública y de la ciencia y subraya el carácter interpretado, reflexionado y apropiado de la adopción de modelos o implementación de políticas públicas, de acuerdo tanto con las creencias preconstituidas de los agentes como de los contextos en los que se las dota de sentido (Clarke, Bainton, Lendvai \& Stubbs, 2015). Las traducciones son inherentes al proceso de transferencia por muy coercitivas que sean las formas; y son necesarias (para persuadir a grupos sociales heterogéneos, para lanzarlas a la escala transnacional y para concretarlas cuando los principios 
transferidos son amplios y vagos) a pesar de que este proceso comporte un riesgo de distorsión, es decir, de adoptar modelos diferentes a los inicialmente previstos.

Así, también los supuestos fracasos en la incorporación de ciertos modelos son interpretados en este marco. Las transferencias incompletas serían, en realidad, el resultado esperado de un proceso de transferencia (Stone, 2017). Constituyen además una oportunidad para el aprendizaje generalmente relegada tanto en los estudios, donde prima la circulación de las buenas prácticas (Lovell, 2019), como en la práctica de la acción pública (Dunlop, 2017).

Por todo ello, los espacios de la formulación e implementación de políticas públicas están lejos de disolverse bajo el influjo de modelos globales, sino que nuevas geografías de la movilidad de políticas públicas se están dibujando. Como observa Brenner y recogen McCann y Ward (2010), la circulación de modelos debe entenderse como una mezcla de procesos: uno de territorialización, donde se dan impactos locales de procesos globales; y otro de desterritorialización, con la adhesión de actores y prácticas localizados a redes globales de circulación de modelos; y, en fin, de reterritorialización, al tratarse de un proceso iterativo.

\subsection{Los estudios sobre europeización y los tipos de transferencias}

Los estudios sobre la europeización han sido un campo prolijo desde el enfoque de la difusión de políticas públicas y han sido emprendidos en primer lugar para explicar los procesos de convergencia (Holzinger \& Knill, 2005). Se ha considerado posteriormente la europeización como un proceso de transferencia de políticas públicas en el que la construcción europea se realiza a golpe de transposición de reglas, procedimientos, paradigmas de política pública, creencias y normas que son, en primer lugar, definidos en el seno político de la UE para luego ser incorporados en la lógica de los discursos, identidades, estructuras y políticas locales (Radaelli, 2003). Del conjunto de estudios sobre la europeización, destacan aquellos que observan las diferentes modalidades de transferencia de políticas públicas e instituciones, conscientes del espacio entre la convergencia de iure y la convergencia de facto, de los contextos más amplios de presión internacional, como los acuerdos de mercado, o de los contextos locales y prismas nacionales con que se adoptan, así como las interacciones múltiples alejadas de las copias literales de arriba abajo (Bomberg \& Peterson, 2000; Bulmer \& Padgett, 2005; Holzinger \& Knill, 2005; Saurugger \& Surel, 2006).

Así, se han tipificado las modalidades de las transferencias en el marco de la UE cruzando algunas variables del marco analítico propuesto por Dolowitz y Marsh (lugar en el continuum, grado y objeto) de forma que existirían tres tipos (Bulmer \& Padgett, 2005) que en numerosas ocasiones coexisten y se refuerzan (Stone, 2012). El primer tipo, obligatorio y normativo, corresponde al "hard transfer" mediante el que tienen lugar, por ejemplo, las transposiciones reglamentarias exactas; el segundo tipo es voluntario y orientado a la importación de ideas, actitudes y principios 
de acción ("soft transfer") de forma más próxima a la emulación o la combinación; y el tercero, de tipo mimético, consiste en una incorporación casi literal de los modelos de forma no coercitiva directa, sino indirecta o voluntaria.

En suma, de esta manera el supuesto efecto de convergencia que mantenían anteriores enfoques entra en contradicción con las hipótesis de esta corriente y los estudios sobre europeización. La movilidad de políticas públicas no provocaría una convergencia absoluta, ni en los principios ni en la práctica de los modelos transferidos, dadas las estructuras y contextos en los que se desarrollan. Incluso las visiones más críticas entrevén aquí los límites propios de la capacidad de reproducción del neoliberalismo (Peck, 2011). Así, el nuevo reto de investigación se deriva de la localización y explicación de la circulación de políticas públicas y modelos, de sus bricolajes, manipulaciones y mutaciones.

\subsection{Las aplicaciones en políticas públicas particulares y algunos vacíos}

Las políticas económicas, medioambientales, sociales y de educación figuran entre las más estudiadas por esta corriente; y, en particular, las políticas urbanas por parte de la geografía (Bok \& Coe, 2017; Cook, 2008; Cook \& Ward, 2011; Gonzalez, 2011; Jajamovich, 2016; McCann \& Ward, 2011; Stead, de Jong \& Reinholde, 2008; Temenos \& McCann, 2012). Estos trabajos se han interesado por los mecanismos de comparación, el papel de los consultores, think tanks y gobiernos en el policy making urbano. Las políticas y modelos turísticos no han sido tratados directamente bajo este enfoque, sino que han ocupado un modesto lugar como contexto: por ejemplo, Ponzinia et al. sostienen que los intereses económicos creados alrededor de este sector suponen un ambiente pujante en el que se desenvuelve la circulación de modelos urbanos transnacionales (2016).

En el ámbito del desarrollo rural, llama la atención que el interés por este enfoque en los pioneros estudios sobre LEADER de Ray (2001a) no se haya desarrollado aún sistemáticamente. Sin embargo, sí que se han aportado pistas de reflexión en cuanto a las condiciones políticoeconómicas de la creación del modelo de desarrollo neoendógeno (Nemes, 2005b); la influencia de los distintos actores involucrados en la manipulación del instrumento (Esparcia Pérez, Noguera Tur, \& Pitarch Garrido, 2000); las diferentes traducciones del modelo LEADER que hace cada sistema político nacional (Chevalier, 2012); y el intercambio de experiencias entre territorios como base para la innovación (Bonfiglio et al., 2017; Cañete, Navarro \& Cejudo, 2018). Todo ello ha puesto en duda la culminación de la implementación del modelo europeo de desarrollo rural. Sin embargo, no existen estudios que sistematicen esta información desde el punto de vista del desarrollo turístico, comprendido en toda su amplitud como área de intervención desde varias políticas públicas. 


\section{El turismo en el medio rural en España visto a través de la transferencia de LEADER y Planes en Destino}

\subsection{LEADER y Planes en Destino: principales instrumentos de fomento del turismo en el medio rural en España}

LEADER es un método de diversificación de la economía rural mediante los postulados del desarrollo neoendógeno que se configura como un verdadero laboratorio de aprendizaje europeo (Esparcia, 2014; Nemes, 2005a; Ray, 2000). El modelo se nutre de consideraciones teóricas y prácticas que promueven un enfoque territorial y no sectorial de la diversificación de la economía rural basado sobre la innovación en la puesta en valor de los recursos territoriales y adaptado a los contextos socioeconómicos particulares dirigido a dar respuesta a las necesidades locales y según las capacidades y las expectativas de la población local creando entornos más democráticos donde se promueve la cooperación institucional y la participación (Esparcia, Escribano \& Serrano, 2015; Ray, 1997; Van Der Ploeg et al., 2000). Para materializar estos principios, se crea un actor colectivo institucionalizado para cada territorio de aplicación denominado Grupo de Acción Local (GAL) y compuesto por agentes del sector público y privado (representantes del gobierno local, asociaciones culturales, deportivas, medioambientales, asociaciones empresariales, empresas y particulares del territorio en cuestión) en cuya Asamblea General de socios debe encontrarse una proporción del 50/50 según establece la Unión Europea. El instrumento LEADER ofrece un amplio margen de maniobra a los GAL a pesar de estar regulados por escalas superiores de decisión (Unión europea, gobierno nacional y autonómicos que regulan las condiciones mínimas de aplicación y financian conjuntamente el programa). El papel de los GAL es el de elaborar una Estrategia de desarrollo local participada y propia para cada territorio en la que se clarifiquen las medidas prioritarias para su desarrollo. A su vez, los GAL seleccionan los criterios de las convocatorias a proyectos con arreglo a la Estrategia y en consonancia con los principios europeos, así como los proyectos que respondan a estas convocatorias favorablemente y que, por tanto, serán financiados por el fondo de LEADER.

En España se vienen aplicando las sucesivas versiones de LEADER en el marco de los Planes Nacionales y los Programas Regionales: de 1991 a 1993 en forma de programa piloto LEADER I; de 1994 a 2006 como Iniciativa Comunitaria LEADER II y LEADER +; de 2007 a 2020 como eje de la Política Europea de Desarrollo Rural, segundo pilar de la PAC. Entre 2014 y 2020 pasa a denominarse "desarrollo local a cargo de las comunidades locales" (DLCL) pues se nutre por primera vez no solo del fondo FEADER sino de otros fondos estructurales como FEDER o FSE. Esta implementación ocupa una porción del territorio creciente que ha cubierto ya la práctica totalidad del territorio elegible, ocupando más del $80 \%$ del territorio nacional y el $26 \%$ de la población (Red Rural Nacional, 2011). 
En todas sus ediciones, la reglamentación que enmarca LEADER promueve el fomento del turismo reservándole una medida propia al lado de otras medidas para el apoyo a las PYMES, a la valorización y comercialización de productos agrarios, al apoyo a la formación y empleo, etc. (Nieto \& Cárdenas, 2015). Uno de los rasgos fundamentales de la aplicación de LEADER es su orientación hacia el turismo desde sus primeras versiones hasta la actualidad (Bull, 1999; Scott, Shorten, Owen \& Owen, 2011), especialmente en España (Cànoves, Garay \& Duro, 2012). Este fenómeno ha llevado a algunos autores a caracterizarlo incluso de mecanismo de turistificación del medio rural en lo que se refiere al sobredimensionamiento de la oferta (Cànoves et al., 2006; Ivars Baidal, 2000; Paül, Lazovski \& Lois, 2016). Pero no ocurre de forma uniforme en el espacio, pues recientes estudios dedicados a la distribución espacial de LEADER dan cuenta de cómo las mayores inversiones turísticas se relegan a las áreas menos dinámicas demográfica y socioeconómicamente que son también aquellas que menores proyectos de transferencia de conocimiento y cooperación ejecutan; es el caso de Andalucía (Cañete et al., 2018) y de Extremadura (Nieto Masot \& Cárdenas Alonso, 2018). De un lado, se confirma así la aplicación diferenciada del método en los territorios, pero de otro, cuestiona la eficacia del modelo de turismo en el medio rural con LEADER al darse en las áreas más vulnerables.

Paralelamente y a lo largo de los años 90, el gobierno nacional arranca un importante trabajo de planificación del turismo por cuenta propia, bajo el paraguas de sus competencias en la planificación y coordinación económica del país. En el marco de los Planes Turísticos del Estado surge la promoción del turismo en el medio rural a través del instrumento de Planes en Destino cuyos territorios en ocasiones se solapan con los perímetros de LEADER. Estos Planes nacen en un triple intento: de diversificación del producto turístico nacional, de extensión de la huella turística a destinos incipientes como oportunidad para el crecimiento económico y de respuesta a la supuesta crisis del "sol y playa". Los Planes en Destino se traducen en convenios tripartitos en los que participan el Ministerio, La Comunidad Autónoma y los Ayuntamientos con la colaboración del sector privado para la planificación territorial del turismo. Han constituido una de las principales áreas de inversión de la Secretaría General de Turismo desde su puesta en marcha en los 90 (Foronda \& García, 2009) y el primer instrumento con enfoque territorial en el marco de una política tradicionalmente sectorial (Velasco González, 2004).

Los primeros planes arrancan en 1993 y hasta 1999 se denominan Planes de Excelencia y Planes de Dinamización Turística en el Plan Marco de Competitividad del Turismo Español I y || (FUTURES I y II), de 2000 a 2006 se refunden en los Planes de Dinamización del Producto Turístico en el Plan de Integral de Calidad del Turismo Español (PICTE); y de 2008 a 2011 pasan a denominarse Planes de Competitividad en el marco del Plan del Turismo Español Horizonte 2020. En 2011, con la llegada del nuevo Plan Nacional e Integral de Turismo desaparecen definitivamente. 


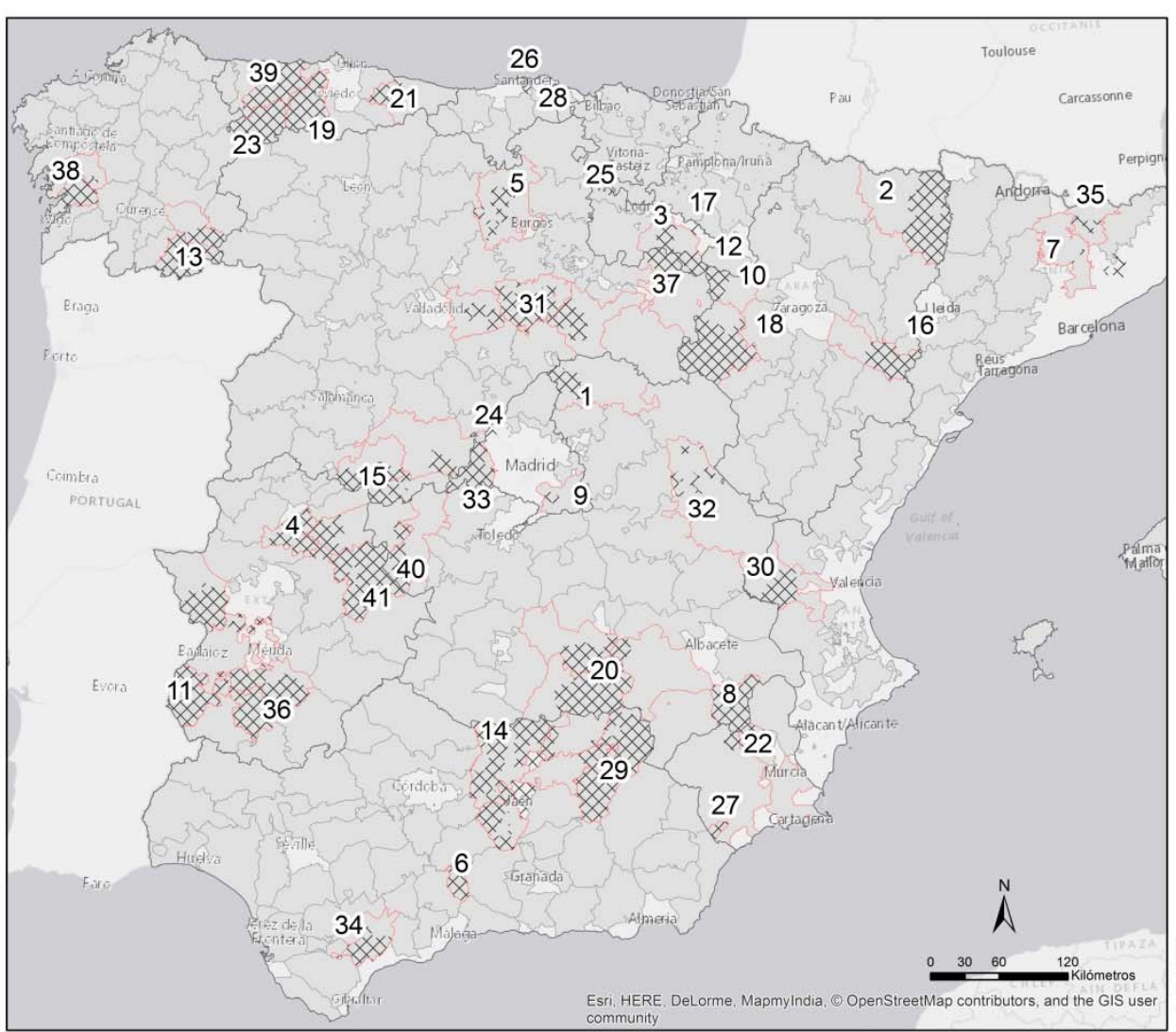

Planes de Competitividad Turística Pueblos de la Arquitectura Negra 2-Comarca de la Ribagorza El Paisaje Humanizado 5-Ruta Cuatro Villas de Amaya 6-Sierra Norte de Málaga - Entre olivos -Bosques de Brujas y Bandoleros 8-Campos de Hellín - Ruta de la Tamborrada Chinchón La Plaza del Tiempo 0-Comarca de Tarazona y el Moncayo 11-Guadina Internacional 3-Puertas de Galicia 3-Puertas de Galicia 5-Sierra de Gredos y batallas de Jaén 5-Sierra de Gre
Turismo Activo

Planes de Dinamización del Producto Turistico 6-Comarca Bajo Aragón-Caspe 7-Calahorra Calatayud la Comunidad 19-Camin Real Me 20-Campo de Montiel 21-Comarca del Sueve -Desfiladero de Almadene 23-Fuentes del Narcea 25-Haro - Patrimonio del Vino 25-Marina de Cudeyo
27-Medina de Nogalte 28-Medio Cudeyo 29-Parque Natural de Cazorla, Segura y Las Villas 30-Requena

1-Ruta del Vino Ribera del Duero 2-Serranía Alta de Cuenca 4-Serranía de Ronda 5-Terrania de Ronda 6-Tierra de Barros-Zafra-Rio Badión 37-Tierras Altas de Soria 8-Tierras de Pontevedra 9-Comarca Vaqueira -Vía Verde de la Jara 1-Villuercas-lbores-Jara

Grupos de Acción Local involucrados XX. Planes en destino desde 2007 Otros Grupos de Acción Local

Nota: este mapa no incluye los Planes en Destino referidos a espacios insulares y de municipios urbanos.

Fuente: elaboración propia basado en Ministerio de Agricultura, Pesca y Alimentación; Turespaña; Boletín Oficial del Estado (varios números)

Inicialmente los planes se aplicaban en destinos litorales maduros de sol y playa. Con el plan Futures II se incorporaron zonas de montaña (valles del Pirineo como Benasque, Tena y Vall de Boí) y con el plan PICTE se incrementó cuatro veces la financiación asignada al programa dándole mayor importancia a los planes implementados en destinos incipientes, principalmente rurales y de interior (Beas Secall, 2014). Del total de Planes en Destino ejecutados en el país, y a pesar de las dificultades de adscripción, se podría considerar que hasta 114 de 265 planes se han desarrollado en localidades y comarcas de ámbito rural.

Los espacios de solapamientos de los instrumentos LEADER y Planes en Destino (ver Figura 1) son áreas sometidas a una doble transferencia de instrumentos de fomento del turismo en el medio rural. Se trata de áreas potenciales de estudio de las diferentes traducciones de ambos instrumentos (articuladas o no en sus objetivos, estrategias y actores) y, por tanto, áreas de gran interés para la aplicación del marco global de la transferencia que se ofrece en el siguiente apartado. 


\subsection{Hacia una caracterización global de la transferencia de LEADER y los Planes en Destino}

Las Tablas 1 a 6 ofrecen una sistematización de los elementos que constituyen la transferencia de los instrumentos LEADER y Planes en Destino en su papel en el fomento del turismo en el medio rural. Se ha tratado la transferencia como variable dependiente, es decir, definiéndose por los elementos recogidos en esta tabla construida sobre la base del marco analítico propuesto por Dolowitz y Marsh (2000). De esta forma, podemos categorizar el tipo de transferencia que nos ocupa sobre la base del tipo de actores involucrados, el grado de obligatoriedad y sentido de la transferencia, la naturaleza de su contenido, el grado de hibridación y los factores que facilitan o constriñen la transferencia.

La transferencia de LEADER y de los Planes en Destino está sujeta a distintos grados de obligatoriedad (ver Tabla 1). Desde una perspectiva evolutiva, tanto LEADER en sus primeras fases como Iniciativa Comunitaria (1991-2006), como los Planes en Destino son instrumentos voluntarios que se solicitan a iniciativa de los ayuntamientos y otros actores locales. Mientras esta característica se mantiene estable en todas las versiones de Planes en Destino, la trayectoria del programa LEADER da un giro a partir de 2007 al convertirse en un eje de obligatoria ejecución de la Política Europea de Desarrollo Rural. Este hecho compele a todos los Estados miembro a ejecutar el método en una porción más o menos significativa de su territorio (algo menos relevante en el caso español pues el territorio elegible estaba ya profundamente afectado a este programa). Este proceso, conocido como "mainstreamization" de LEADER (Dax, Strahl, Kirwan, \& Maye, 2016), reconoce cambios de calado que endurecen su aplicación y que han sido avalados por el Tribunal de Cuentas Europeo (European Court of Auditors, 2010): como la mayor complejidad del nuevo marco regulador, los retrasos para iniciar su ejecución, la dificultad para dar cabida a las iniciativas percibidas como necesarias a nivel local y la influencia de la crisis económica y financiera. Bien es cierto que ninguno de los instrumentos ejerce un poder coercitivo sobre el desarrollo del turismo en el medio rural. La realidad apunta a que la implementación de estos planes para el desarrollo turístico está esencialmente justificada por la oportunidad de recibir las ayudas disponibles y por la percepción de su pertinencia. 
Tabla 1. Grado de obligatoriedad

\begin{tabular}{|c|c|}
\hline LEADER & PLANES EN DESTINO \\
\hline $\begin{array}{l}\text { Voluntario, pero progresivamente más coercitivo. } \\
\text { Totalmente voluntario como Programa piloto (1991-1993), } \\
\text { aunque la Comisión de las Comunidades Europeas animaba a la } \\
\text { implementación en algunos países como España (Smith, 1996). } \\
\text { También lo era como Programa de Iniciativas Comunitarias } \\
\text { (1995-2006) (Ray, 2001a). A partir de 2007, entra a formar } \\
\text { parte de la Política Agraria Común y es de obligada } \\
\text { implementación por todos los Estados miembro (Dax et al., 2016), } \\
\text { aunque el margen de maniobra para la formulación final del } \\
\text { instrumento sigue dependiendo de cada Estado (como eje } 4 \\
\text { 2007-2013 y como Desarrollo a cargo de Comunidades Locales } \\
\text { 2014-2020) siendo en el caso español un ejemplo de } \\
\text { formulación fundamentalmente descentralizada (Chevalier, 2012; } \\
\text { Dax et al., 2016; Yubero, 2017). }\end{array}$ & $\begin{array}{l}\text { Desde su nacimiento en } 1995 \text { hasta su } \\
\text { desaparición en 2011, ha sido un } \\
\text { instrumento voluntario en su aplicación: } \\
\text { a iniciativa local, pero sometido a } \\
\text { proceso competitivo de evaluación y } \\
\text { selección por parte de las } \\
\text { Comunidades Autónomas primero y } \\
\text { por parte de la Conferencia Sectorial } \\
\text { de Turismo después (órgano colegiado } \\
\text { de los Ministerios con competencias en } \\
\text { materia de turismo) después. }\end{array}$ \\
\hline
\end{tabular}

Fuente: elaboración propia

Tabla 2. Agentes involucrados

\begin{tabular}{|c|c|}
\hline LEADER & PLANES EN DESTINO \\
\hline $\begin{array}{l}\text { Organismos internacionales (OCDE y OMC entre } \\
\text { otros) (Freshwater \& Trapasso, 2014); Unión europea } \\
\text { (Nemes, 2005b); Gobierno nacional, autonómico y } \\
\text { local (Chevalier, 2014; Esparcia Pérez et al., 2000; } \\
\text { Yubero, 2017); tejido socioeconómico local (García } \\
\text { Marín, 2011); élites locales profesionales y políticas, } \\
\text { en ocasiones en forma de redes vagas en torno a } \\
\text { valores comunes o alianzas ad hoc (Ray, 2001); los } \\
\text { propios miembros del GAL en viajes técnicos y en } \\
\text { proyectos transnacionales (Ray, 2001b; Tirado } \\
\text { Ballesteros \& Hernández, 2018); Red Europea de } \\
\text { Desarrollo Rural (ENRD), Red Nacional de Desarrollo } \\
\text { Rural-RNDR (y las autonómicas que la conforman) } \\
\text { desde 2008; Empresas consultoras (Kovách \& } \\
\text { Kučerová, 2006); sociedad civil (Paül, 2013). }\end{array}$ & $\begin{array}{l}\text { Gobierno nacional (diseño del Programa en los } \\
\text { Planes nacionales); Gobierno nacional y } \\
\text { autonómico a través de la Conferencia Sectorial } \\
\text { de Turismo; Ayuntamientos; Federación de } \\
\text { Municipios y Provincias (FEMP) (Beas Secall, } \\
\text { 2014); asociaciones empresariales específicas del } \\
\text { sector, generalistas, trasversales como cámaras de } \\
\text { comercio, o consorcios público-privados (Beas } \\
\text { Secall, 2014); consultoras y empresas privadas } \\
\text { de planificación y gestión turística (Foronda \& } \\
\text { García, 2009); Unión Europea (indirectamente a } \\
\text { través del apoyo con el fondo FEDER y del trabajo } \\
\text { de la consultora belga OGM para la Comisión } \\
\text { europea en } 2000 \text { para la creación de SICTED). }\end{array}$ \\
\hline
\end{tabular}

Fuente: elaboración propia

Los actores involucrados en la transferencia estos instrumentos son de muy diversa naturaleza y con un grado de influencia variable (ver Tabla 2). Los organismos internacionales como la Organización para la Cooperación y el Desarrollo Económicos (OCDE) y la Organización Mundial del Comercio (OMC) juegan un papel preponderante en la persuasión de que el turismo es una actividad con futuro en el medio rural europeo. En cuanto a LEADER, la Unión Europea se corresponde con el actor emisor del instrumento (que diseña y transfiere) mientras que en los Planes en Destino lo es el Gobierno nacional a través de la Secretaría General de Turismo. 
En su implementación están directamente implicados, por normativa, todos los niveles de gobierno: nacional, autonómico y local tanto en uno como en otro instrumento. Además, se solicita la participación, también obligatoria, del sector privado ya sea de forma aislada (empresas) como colectiva (asociaciones empresariales). Las empresas consultoras están directamente implicadas en la elaboración de los planes de desarrollo a nivel nacional, regional y local (en el caso de LEADER) y local (en el caso de los Planes en Destino), entrando a formar parte de la "nueva clase de proyectos", nuevas élites locales (Kovách \& Kučerová, 2006). Por último, y solo en el caso de LEADER, existe una red creada en 2008 y apoyada por la UE que se encarga específicamente de la transferencia de conocimiento y buenas prácticas basadas en la implementación de LEADER, la European Network for Rural Development (ENRD). Esta red mantiene una intensa actividad en la difusión de experiencias de desarrollo turístico en particular: con publicaciones específicas y casi un tercio de los proyectos e iniciativas que sirven de modelo en el periodo 2014-2020 (www.enrd.es.europa.eu).

El contenido de la transferencia puede dividirse en elementos materiales, principalmente fondos, los propios reglamentos y protocolos de seguimiento y evaluación; e inmateriales como poder y legitimidad, principios de actuación, metodologías de planificación, ideas, discursos, argumentos y representaciones (ver Tabla 3). Todo ello puede definirse como modelos de desarrollo del turismo en el medio rural cuyas formas presentan contornos borrosos y que se estudian en el siguiente apartado. La indefinición del modelo de turismo rural perseguido intensificaría el papel de las traducciones locales en su formulación final como apuntaban algunos autores (Oliveira, 2018).

La transferencia de estos instrumentos es ciertamente multiescalar (ver Tabla 4). El mecanismo de difusión se da en sentido vertical, atravesando varias escalas de actuación, y en sentido horizontal entre áreas de actuación a la misma escala, fundamentalmente local. El sentido vertical es esencialmente top-down tal y como se especifica en la regulación de ambos instrumentos, con mayor o menor grado de subsidiariedad. Sin embargo, también se incluye un procedimiento bottom-up, pero que en la práctica resulta menos significativo de lo que traslucen los principios de la planificación. Con la recepción de estos instrumentos elaborados a escala europea, los territorios locales quedan conectados al flujo europeo de ideas sobre el desarrollo rural y a la política nacional turística y, con el intercambio de experiencias a nivel local, los territorios tejen una red propia que, a su vez, concreta y reformula los preceptos europeos. Este mecanismo es más fuerte en el caso de LEADER que en el caso de los Planes en Destino, no solo por su alcance sino también por la mayor institucionalización de este mecanismo. 
Tabla 3. Elementos transferidos

\begin{tabular}{|c|c|c|}
\hline & LEADER & PLANES EN DESTINO \\
\hline $\begin{array}{c}\text { Material: } \\
\text { instrumentos } \\
\text { de política } \\
\text { pública }\end{array}$ & $\begin{array}{l}\text { Fondos (FEOGA-O desde } 1991 \text { hasta 2007; } \\
\text { FEADER desde } 2007 \text { hasta 2020; FEADER } \\
\text { además de otros fondos estructurales desde } \\
2014 \text { a 2020) y principio de corresponsabilidad } \\
\text { financiera entre la Unión Europea y los Estados } \\
\text { miembro; reglamentos que incluyen un "menú } \\
\text { de medidas" a elegir entre las que siempre se } \\
\text { encuentra el fomento del turismo (principalmente } \\
\text { a través de la adecuación del patrimonio y de la } \\
\text { creación de oferta como el alojamiento); } \\
\text { protocolo de seguimiento y evaluación con } \\
\text { indicadores fijos. }\end{array}$ & $\begin{array}{l}\text { Convenio tripartito de obligado } \\
\text { cumplimiento con objetivos generales y } \\
\text { un programa de actuaciones; fondos y } \\
\text { corresponsabilidad financiera de los } \\
\text { tres niveles de gobierno (Estado, } \\
\text { Comunidad Autónoma y } \\
\text { Ayuntamiento); protocolo de actuación } \\
\text { y seguimiento; en algunos casos, se } \\
\text { incluía el Sistema Integral de Calidad } \\
\text { Turística en Destino (SICTED). }\end{array}$ \\
\hline Inmaterial & $\begin{array}{l}\text { Poder hacia lo local y legitimación institucional } \\
\text { (Lacquement \& Chevalier, 2016; Ray, 1999); } \\
\text { cesión excesiva de responsabilidad hacia lo local } \\
\text { (Cheshire, Esparcia, \& Shucksmith, 2015); } \\
\text { principios y técnicas del desarrollo } \\
\text { neoendógeno pero encastrados en el sistema } \\
\text { capitalista neoliberal sin cuestionarlo del todo } \\
\text { (Nemes, 2005a; Osti, 2015; Ray, 2001a); } \\
\text { discurso de la adecuación del turismo para la } \\
\text { diversificación de la economía rural y el } \\
\text { desarrollo en línea con la OCDE (1994, 2018); } \\
\text { experiencias positivas (Ray, 2000); sentimiento } \\
\text { de solidaridad rural a modo de lobby europeo } \\
\text { (Ray, 2001a). }\end{array}$ & $\begin{array}{l}\text { Discurso de la necesaria diversificación } \\
\text { del producto turístico español incluido } \\
\text { en el marco de los Planes Nacionales; } \\
\text { legitimización de la escala local de } \\
\text { actuación (Calle Vaquero \& García } \\
\text { Hernández, 2016); argumento sobre } \\
\text { la eficacia de la participación privada y } \\
\text { compromiso del sector turístico en la } \\
\text { competitividad; método de } \\
\text { planificación bajo un enfoque integral } \\
\text { del "destino" (Velasco González, } \\
\text { 2004) donde prevalece una visión } \\
\text { comarcal y estratégica (Calle Vaquero } \\
\text { \& García Hernández, 2016; Foronda } \\
\text { \& García, 2009; Ivars Baidal, 2004). }\end{array}$ \\
\hline
\end{tabular}

Fuente: elaboración propia 
Tabla 4. Escalas de la transferencia

\begin{tabular}{|c|c|c|}
\hline & LEADER & PLANES EN DESTINO \\
\hline Del pasado & $\begin{array}{l}\text { Propia experiencia española pasada: los GAL se } \\
\text { construyen, en ocasiones, sobre la base de estructuras } \\
\text { organizativas institucionalizadas preexistentes (Delgado } \\
\text { Viñas, 2007). Experiencia adquirida de los GAL desde } \\
\text { que arrancan con la implementación de LEADER. }\end{array}$ & $\begin{array}{l}\text { Experiencias pasadas en otro } \\
\text { tipo de espacios (industriales } \\
\text { como zonas mineras (Brunet, } \\
\text { Almeida, Coll, \& Monteserín, } \\
\text { 2005). }\end{array}$ \\
\hline $\begin{array}{l}\text { Entre } \\
\text { distintas } \\
\text { escalas de } \\
\text { actuación }\end{array}$ & $\begin{array}{l}\text { Transferencia top-down de tipo normativo, impuesto por la } \\
\text { propia reglamentación europea, en sentido: UE, España, } \\
\text { Comunidades autónomas, LAG, población local. }\end{array}$ & $\begin{array}{l}\text { Transferencia top-down, de tipo } \\
\text { normativa e impuesta por la } \\
\text { propia regulación de los Planes } \\
\text { en Destino (Estado, Comunidad } \\
\text { Autónoma, Ayuntamientos) }\end{array}$ \\
\hline $\begin{array}{c}\text { Entre } \\
\text { ámbitos de } \\
\text { actuación a } \\
\text { escalas } \\
\text { iguales } \\
\text { (sentido } \\
\text { horizontal) }\end{array}$ & $\begin{array}{l}\text { El intercambio de experiencias positivas y el efecto } \\
\text { demostración forma parte de la "filosofía LEADER" y está } \\
\text { aconsejado en su reglamentación. Para el desarrollo de } \\
\text { este principio (efecto demostración y capacidad de } \\
\text { transferencia de las experiencias) se crean los Proyectos } \\
\text { de Cooperación Interterritorial entre GAL de un mismo } \\
\text { Estado; los Proyectos de cooperación Transnacional entre } \\
\text { GAL de diferentes Estados. Además, a través del } \\
\text { Observatorio LEADER (1993-2007) y de la posterior } \\
\text { ENRD y RNDR (desde 2008) u otras redes sectoriales } \\
\text { como la "Red de Turismo ornitológico" también se } \\
\text { seleccionan, intercambian y aplican experiencias y } \\
\text { "buenas prácticas". Por último, existe transferencia de } \\
\text { LEADER hacia países iberoamericanos (mediada por } \\
\text { instituciones como el Fondo Internacional de Desarrollo } \\
\text { Agrícola o el Banco Interamericano de Desarrollo). }\end{array}$ & $\begin{array}{l}\text { Otras experiencias de Planes en } \\
\text { Destino entre comarcas o } \\
\text { localidades próximas en sentido } \\
\text { amplio (geográfico, tipología de } \\
\text { territorio, agentes involucrados). }\end{array}$ \\
\hline
\end{tabular}

Fuente: elaboración propia

Todos los factores facilitadores de las transferencias, o que las dificultan, y que se recogen en la Tabla 5 se refieren a los contextos de difusión e implementación, como la percepción de una necesidad, el desconocimiento del sector turístico, las trayectorias de aprendizaje, etc. Esto supone que el grado de hibridación que se espera de la transferencia de estos instrumentos responde más a la mencionada traducción, adaptación y el ensamblaje que a la copia literal (ver Tabla 6). 
Tabla 5. Factores que facilitan y factores que dificultan la transferencia

\begin{tabular}{|c|c|c|}
\hline & LEADER & PLANES EN DESTINO \\
\hline & $\begin{array}{l}\text { Contexto político-administrativo centralizado como } \\
\text { en el caso centroeuropeo (Chevalier, 2014; Panyik, } \\
\text { Costa, \& Rátz, 2011); estructuras de poder público } \\
\text { local y regional que tienden a apropiárselo en } \\
\text { beneficio propio como ocurre en España (Esparcia } \\
\text { Pérez et al., 2000; Tirado Ballesteros \& } \\
\text { Hernández, 2018); percepción de una creciente } \\
\text { complejidad, regulación y control (Dax et al., 2016; } \\
\text { Navarro, Woods, \& Cejudo, 2016; Tirado } \\
\text { Ballesteros \& Hernández, 2018); desconocimiento } \\
\text { del mercado turístico (Ivars Baidal, 2000) } \\
\text { especialmente tangible en el sistema de evaluación } \\
\text { (Tirado Ballesteros \& Hernández Hernández, 2017). }\end{array}$ & $\begin{array}{l}\text { Mal entendimiento de la filosofía: apropiación } \\
\text { en beneficio propio (por ejemplo, del } \\
\text { gobierno local para invertir en equipamientos y } \\
\text { obras públicas (Domingo, Martínez, \& } \\
\text { Araque, 2012; Foronda \& García, 2009); } \\
\text { visión cortoplacista (Brunet et al., 2005); } \\
\text { contexto social local: conflictos con el sector } \\
\text { privado, escaso entramado asociativo previo o } \\
\text { desconfianza del empresariado hacia el } \\
\text { turismo público (M.J. González, 2002; Sebrià, } \\
\text { 2002, citados en Brunet et al., 2005); mal } \\
\text { entendimiento del mercado turístico } \\
\text { (Valenzuela, García, \& Giralt, 2008) } \\
\text { especialmente tangible en el deficiente } \\
\text { seguimiento (Brunet et al., 2005). }\end{array}$ \\
\hline 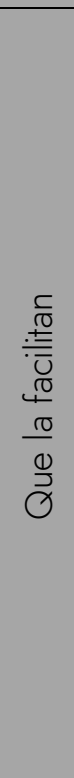 & $\begin{array}{l}\text { Contexto de crecimiento del mercado turístico en el } \\
\text { medio rural (finales } 90 \text { y principios 2000); } \\
\text { contexto territorial local favorable por la presencia } \\
\text { de recursos o por la larga trayectoria turística } \\
\text { (Hernández Hernández, 2008; Nieto Masot \& } \\
\text { Cárdenas Alonso, 2017; Zasada \& Piorr, 2015); } \\
\text { contexto político-administrativo descentralizado (Ivars } \\
\text { Baidal, 2000; Rosell \& Viladomiu, 2012); } \\
\text { convencimiento de lo apropiado del turismo como } \\
\text { mecanismo de desarrollo neoendógeno (Cànoves } \\
\text { et al., 2006; Pitarch \& Amandís, 2014; Solsona \& } \\
\text { López, 2012); disponibilidad de fondos (Esparcia } \\
\text { Pérez et al., 2000); contexto territorial demográfica } \\
\text { y socioeconómicamente poco dinámico (Cañete et } \\
\text { al., 2018; García Marín, 2011; Nieto Masot \& } \\
\text { Cárdenas Alonso, 2018). }\end{array}$ & $\begin{array}{l}\text { Disponibilidad de fondos (Barrado, } 2007 \text { en } \\
\text { Valenzuela et al., 2008); Existencia de } \\
\text { estrategias previas de filosofía similar, como } \\
\text { LEADER (Álvarez et al., } 2002 \text { citado en Brunet } \\
\text { et al., 2005). }\end{array}$ \\
\hline
\end{tabular}

Fuente: elaboración propia 
Tabla 6. Grado de la transferencia

\begin{tabular}{|l|l|}
\hline \multicolumn{1}{|c|}{ LEADER } & PLANES EN DESTINO \\
\hline Todas las referencias incluidas en las tablas previas & Copia literal (Martín \& Martín, 2014); el resto de las \\
aluden, aunque no siempre explícitamente, a una & referencias incluidas en las tablas previas aluden, \\
traducción (interpretada y mediada) del instrumento & aunque no siempre explícitamente, a una traducción \\
LEADER para el fomento del turismo en el medio & (interpretada y mediada) de los Planes en Destino \\
rural, cuando parece no existir ninguna referencia & para el fomento del turismo en el medio rural. \\
acerca de la copia literal consciente. & \\
\hline
\end{tabular}

Fuente: elaboración propia

En síntesis, la transferencia de LEADER como mecanismo de fomento del turismo en el medio rural en España se asimila a un tipo de "soft transfer", aunque en menor medida que los Planes en Destino. A partir de 2007 adopta un carácter más coercitivo, como se ha explicado anteriormente: tienen lugar transposiciones reglamentarias exactas y obligatorias (con el fin de garantizar una implementación harmoniosa con los principios de la UE), pero, en consonancia con el propio modelo de desarrollo neoendógeno basado fundamentalmente en ideas, actitudes y principios de acción, el margen de maniobra de los Estados miembro y, sobre todo, de los GAL se mantiene amplio. La transferencia de los Planes en Destino está sin duda relacionada con el tipo "soft" pues no existe normativa específica más allá de los convenios programáticos muy amplios en sus objetivos y limitados al reparto de responsabilidades.

\subsection{Modelo(s) de turismo rural en los instrumentos LEADER y Planes en Destino}

La Comunidad Europea (CE), y posterior Unión Europea (UE), incluye el turismo en su modelo de desarrollo rural desde 1988. Por constituir la agricultura una competencia europea y no así el turismo, el enfoque (post)agrario sobre el turismo rural predomina sobre el enfoque turístico en la elaboración del argumentario (Blanco Herranz, 1996). Para la UE, el ocio se configura como la principal oportunidad para el desarrollo económico de las áreas rurales con base en una serie de postulados explícitos en dos pioneras declaraciones: "El futuro del mundo rural" (Comisión de las Comunidades Europeas, 1988) y la Declaración de Cork (European Union, 1996). Se declara así al turismo como principal motor de desarrollo de las zonas marginadas porque responde a una demanda real, contribuye a la salvaguarda del patrimonio a la vez que sirve de activo económico y crea empleos complementarios y alternativos a la agricultura; siendo la asociación de los agentes locales el método idóneo para aprovechar el potencial local del desarrollo turístico. Sobre este discurso, que apenas sufre variaciones durante la última crisis económica (European Union, 2016), se fragua el modelo europeo de turismo rural.

La UE no ofrece una definición clara de la modalidad como así lo indicaba Eurostat (Blanco Herranz, 1996). Se trataba ya en 1988 de promover no solo el agroturismo, sino todo tipo de 
actividad turística en las áreas de intervención LEADER. El modelo de turismo rural que transfiere la UE presenta contornos borrosos, pero su inclusión en el instrumento LEADER permite inferir una definición a partir de la descripción basada en Ray (2000) del método de su implementación: la integración de la medida sobre turismo rural en el marco de LEADER se puede interpretar como la voluntad de la UE de asegurarse una explotación local y asociativa (a través de los GAL) de la riqueza turística en función de las necesidades, capacidades y expectativas de las poblaciones locales, de forma innovadora y de efecto demostrable y transferible.

Del análisis de la reglamentación europea de los dos últimos periodos (2007-2013 y 20142020), se observa una tendencia que ahonda su carácter más genérico y transversal a la vez que se orienta en mayor medida a los segmentos específicos para superar la histórica orientación de los territorios hacia la proliferación de la oferta de alojamiento. Por ejemplo, sus directrices estratégicas en 2007-2013 han mantenido el apoyo al turismo esgrimiendo que "El turismo, la artesanía y las actividades recreativas (...) ofrecen oportunidades tanto para la diversificación de las explotaciones agrícolas en actividades distintas de la agricultura como para el desarrollo de microempresas en la economía rural, en sentido amplio" (Consejo Europeo, 2006, vol. L 55/26).

Por transversal, se entiende la apuesta de la Dirección General de Agricultura de la Comisión Europea (DG Agri) por incluirse en todos los ejes de la Política Europea de Desarrollo Rural. En la Guía para la aplicación de LEADER, la propia DG Agri de la Comisión Europea orienta a que la inversión en turismo encuentre cabida en todos los ejes de la política como oportunidad de posicionamiento en nuevos mercados para las producciones locales de bienes y servicios de todo tipo (Directorate-General for Agriculture, 2011). Esta transversalidad también se observa en que preservar el potencial turístico de una zona se convierte en un argumento relevante para las ayudas en materia de conservación de la naturaleza y patrimonio cultural en el Reglamento 1305/2013 relativo al FEADER. Además, en el periodo 2014-2020 se promueven actividades de fomento del turismo no solo para atraer turistas internacionales o nacionales, sino también los propios locales, extendiendo las actuaciones en materia de turismo al ocio de la población local. Esta transversalidad solo está contrarrestada por una mayor atención a los planes de viabilidad empresarial, a la duración determinada de la financiación de un mismo negocio y a la implementación de indicadores más orientados a los segmentos del turismo rural.

En el caso de la Política turística, el modelo de turismo rural que se transfiere ha ido variando en función de la orientación que se les ha otorgado en cada uno de los Planes Nacionales que se han sucedido. En el Plan FUTURES, se define como un tipo de turismo, por oposición a otros tipos que desde los años 90 también se impulsan: turismo urbano, turismo cultural, turismo idiomático, etc. (Secretaría General de Turismo, 1992). La Secretaría General de Turismo lo considera enlazándolo de manera directa con el modelo de desarrollo rural europeo: por su naturaleza difusa (opuesta a la 
masificación), por la puesta en valor del patrimonio cultural y natural, por la participación de la población local y por el mantenimiento de actividades tradicionales en el medio. En el último Plan que mantiene los Planes en Destino, el Plan Integral de Calidad Turística de España, la Administración turística menciona el hecho de que "el desarrollo turístico español ha adolecido de problemas estructurales que, como la estacionalidad y el monocultivo de un solo producto turístico, basado en el sol y playa, aconsejan insistir en una política de diversificación que base el crecimiento del mercado turístico español en la actividad en temporada baja, atrayendo nuevos segmentos de demanda, y la potenciación de nuevos productos turísticos en zonas de desarrollo emergente" (Secretaría General de Turismo, 2000). En esta orientación al mercado tiene lugar la progresiva orientación al producto de los Planes en Destino sucesivos.

Durante la primera fase del programa (de 1998 a 2005) se aprueban los denominados Planes de Excelencia (PET) y Dinamización Turística (PDT); los primeros orientados a la regeneración y recuperación de destinos maduros y los segundos al impulso de destinos emergentes, prácticamente todos en ámbito rural. Por tanto, no se impone un modelo de turismo en el medio rural relacionado con una modalidad específica (agroturismo, ecoturismo, turismo cultural, turismo activo, etc.), sino que sus criterios se decantan por el tipo de espacio o trayectoria del modelo cíclico de Butler donde se van a implementar. En 2005 los PET y los PDT quedaron refundidos dentro de los Planes de Dinamización del Producto Turístico (PDPT), orientados a destinos en desarrollo y centrados fundamentalmente en la creación de productos directamente comercializables a partir de los recursos y empresas existentes. En esta misma línea, la tercera y última fase arranca en 2008 con la puesta en marcha de los nuevos Planes de Competitividad Turística (PCT) que se desarrollan sobre la base de rutas y productos temáticos que vertebren recursos de alto potencial. Se ha pasado de un enfoque de planificación integral del destino a enfoques más orientados a la articulación y comercialización de productos específicos en torno a los cuales se crea o reorienta la oferta y el atractivo de los destinos. Ejemplifica muy bien ese cambio de enfoque las denominaciones de algunos de los Planes de Competitividad Turística aprobados: "Águilas - El Mar y la Pesca", "La Seu d'Urgell - Espacio Ermengol", o "Bosques de Brujas y Bandoleros". Estos productos han tenido un soporte territorial cada vez más difuso y discontinuo. De hecho, los planes aprobados en los últimos años del programa muestran una tendencia a focalizar la atención sobre territorios cada vez más amplios con el fin de dar visibilidad y coherencia a actuaciones conjuntas que puedan superar los estrangulamientos y limitaciones de gestión de la administración local del medio rural. Es por ello por lo que estos planes tienden a tomar como interlocutoras a las secciones de desarrollo rural de las diputaciones provinciales, a entidades ya consolidadas (comarcas o mancomunidades muy activas) o a otras entidades supralocales más potentes. 


\section{Discusión y conclusiones}

En un contexto de acelerada circulación de políticas públicas urgía considerar sistemáticamente la producción de espacios del turismo en el medio rural bajo el enfoque de las trasferencias de políticas públicas; es decir, pensando, como aquí se ha propuesto, el turismo rural como modelo puesto en movimiento por varias políticas públicas y sujeto a traducción a cada paso. De este modo, la presente investigación utiliza un enfoque novedoso en la literatura española para analizar la implementación de dos de los principales instrumentos públicos de fomento del turismo rural considerando las distintas escalas, actores, mecanismos que facilitan y dificultan la transferencia, así como los modelos circulantes y cambiantes a lo largo del tiempo que los sustentan.

La principal aportación de esta investigación ha sido ofrecer por primera vez expresamente, y recogiendo el testigo lanzado por Ray (2001), un marco global dentro del cual poder entender el papel de las transferencias de los instrumentos LEADER y Planes en Destino (tanto verticales, desde las escalas europea y nacional hasta lo local, como horizontales, en el intercambio de experiencias). Con ello, se ha contribuido al traslado del foco de interés desde los estudios estadísticos de escala regional hacia los estudios de caso que teoricen sobre la transferencia como proceso político en el que intervienen distintos actores, intereses y que genera diferentes territorialidades (Peck \& Theodore, 2010; Stone, 2017).

A nivel disciplinario, esta investigación ha contribuido en los estudios de ciencias políticas al aproximarse desde una disciplina diferente, como proponían varios autores, y al caracterizar la transferencia como variable dependiente teniendo en cuenta más de una única política pública o programa, lo que constituye una novedad (Dussauge-Laguna, 2013; McCann \& Ward, 2013; Stone, 1999). Además, se ha combinado la revisión de los estudios de desarrollo rural con la literatura sobre turismo tal y como se sugiere en las últimas revisiones acerca del tema (Carson, 2018).

El presente trabajo contribuye también en la teoría y práctica de los estudios del turismo en el medio rural. En el plano teórico, se ha puesto en evidencia que el desarrollo turístico no puede leerse en clave de modelos únicos de desarrollo (el turismo en el medio rural no es solo LEADER), como se ha demostrado en otros sectores (Galdeano-Gómez, Aznar-Sánchez, \& Pérez-Mesa, 2011), pero tampoco de forma desvinculada de los condicionantes de la transferencia (qué actores los promueven, qué modelos vehiculan, qué grado de obligatoriedad existe en su aplicación, etc.). Tres han sido las principales conclusiones al respecto.

En primer lugar, se ha demostrado cómo aun incluyendo un marco reglamentario más o menos definido por las Políticas que los acogen, LEADER y Planes en Destino ponen en circulación ideas, actitudes y principios de acción confiriéndoles el carácter de transferencia "soft". Por ello, la influencia de los contextos en el proceso de implementación es determinante del modo en que se 
aplican los preceptos del desarrollo turístico. Resulta, por tanto, relevante estudiar qué factores determinan que unos contextos asimilen mejor que otros estas ideas, principios y actitudes.

En segundo lugar, el carácter "soft" de esta transferencia no deja un espacio completamente libre de interpretación, sino que el desarrollo turístico de los espacios rurales está sometido a una doble tensión entre el modelo europeo de desarrollo neoendógeno de LEADER y el modelo de los Planes en Destino, más orientado al objetivo de posicionarse en los mercados exteriores, sobre la base de recursos locales. Así, la transferencia de LEADER y Planes en Destino ha tenido diferente calado en los territorios españoles. La implementación de LEADER ha asegurado una continuidad de los programas y líneas de subvención asociadas al turismo suficiente como para asentar un proceso de aprendizaje ajustado a sus posibilidades reales de desarrollo. Este proceso viene sustentado por un actor colectivo institucionalizado, el GAL. Más o menos representativo de los intereses del sector turístico o de los poderes públicos, los GAL han hecho acopio de experiencia para las traducciones que las distintas ediciones de LEADER iba poniendo a prueba. A pesar de los retrasos en el procedimiento y de la tensión sobre su recentralización, LEADER sigue su curso. Los Planes en Destino, sin embargo, han tenido una menor continuidad espacial y temporal; sometidos a la Política Turística nacional han sufrido reformulaciones de gran calado y su presupuesto y alcance geográfico ha sido más limitado. Los territorios más competitivos a juicio de la Conferencia Sectorial se han beneficiado, como mucho, de un Plan durante 4 ○ 5 años. La gerencia del Plan no ha contado con un actor colectivo institucionalizado, sino que en la mayoría de las ocasiones se ha externalizado a empresas consultoras siendo, en el mejor de los casos, el gerente el enlace con el comité de seguimiento. Esta debilidad de los Planes en Destino se intensifica cuando en 2011 desaparecen de la línea política nacional.

En tercer lugar, aunque tanto desde la actuación de la Política Turística como de la Política de Desarrollo Rural Europea se ha franqueado un salto cualitativo en sus instrumentos para promover una acción pública turística territorializada y estratégica, las formas de la transferencia están aún constreñidas por la falta de un modelo de turismo rural claramente definido. Se han observado importantes divergencias en la consideración que del medio rural tiene la política turística y que del turismo hace la política de desarrollo rural. La Política Turística nacional ha pasado de enfoques de actuación que enlazaban con la lógica del desarrollo local (y en parte, por tanto, con la lógica de la Política Europea de Desarrollo Rural) a una lógica de mercado de perspectiva más sectorial que relega el desarrollo territorial a los objetivos generales de diversificación del producto turístico español. En cambio, para la Política Europea de Desarrollo Rural, el turismo continúa planteándose con base en modelos que lo conciben como una estrategia de diversificación de la economía rural; llegando en la actualidad, a incorporarse como medida transversal en el discurso sobre el desarrollo rural. En esta circunstancia, cabe esperar como adelanta Vázquez Barquero (2016) que solo allí donde haya habido cierto solapamiento organizativo en la gestión de ambos instrumentos 
(por ejemplo, aquellos Planes en Destino con participación de los GAL y que hayan servido para complementar las estrategias locales de desarrollo) pueda haber cierta convergencia en el modelo implementado. En el resto de los casos, los territorios han tenido que enfrentarse a lógicas de intervención en materia turística en el medio rural que responden en parte a distintos objetivos y que dejan varios interrogantes abiertos en los nuevos periodos de programación. En este sentido, las áreas referidas en la Figura 1 constituyen un ejemplo a partir de 2007 de potenciales casos de estudio.

En un sentido práctico, este trabajo, que ha evidenciado las escasas evidencias en la literatura de posibles transferencias horizontales (entre los propios GAL y entre éstos y los gestores de los Planes en Destino) reconoce la idea de que un mayor intercambio de experiencias, volviendo la vista atrás y analizando la implementación de pasados Planes en Destino, puede ser la clave para mejorar la innovación y renovar el "cansancio" de los GAL al respecto (Esparcia, Escribano \& Serrano, 2015). Sería interesante estudiar las prácticas locales de ensayo-error de los modelos de desarrollo turístico aplicados con LEADER y con los Planes en Destino y su calado en el proceso de aprendizaje del desarrollo turístico en el medio rural.

A partir de la última crisis económica se abre un nuevo contexto en el que el impulso público del turismo rural continúa buscando nuevas estrategias de revitalización. Las tendencias observadas revelan un importante retraimiento de la administración turística con la desaparición de los Planes en Destino en 2011 y la inexistencia hasta el momento de instrumentos que los sustituyan en términos parecidos. Por su parte, LEADER encuentra en el último periodo un nuevo engranaje en la Política europea y adopta una regulación más compleja. Pero corren tiempos de desregulación neoliberal y generación de negocios donde las técnicas de mercado son ampliamente preconizadas con base en estudios de consultoría de rango nacional e internacional. Esta tendencia expansiva no viene sino a retroalimentar de nuevo el mito de la "panacea turística" que choca con realidades territoriales muy diversas entre las que es posible encontrar situaciones incipientes de actividad turística difícilmente viable, pero también realidades de uso turístico intensivo que manifiestan evidentes signos de agotamiento por saturación. El fin del enfoque estratégico y territorial parece propiciar la tendencia expansiva del mercado en vez de las actuaciones de contención y renovación de los destinos turísticos viables en el medio rural. Si no cambia la situación, cabe esperar que sea en el ámbito privado donde se acelere la circulación de ideas, instrumentos y principios de acción. Por ello y, por último, se propone el estudio del papel de los actores no gubernamentales en la transferencia de "buenas prácticas" que el retraimiento de la actuación de la administración pública favorece: como la Red Europea de Desarrollo Rural, los consorcios turísticos público-privados o las asociaciones turísticas existentes en cada uno de los territorios de implementación de LEADER y Planes en Destino. Se trataría de conocer no solo qué actores participan en cada uno de los casos de transferencia estudiados, sino qué factores influyen en la selección y difusión de sus prácticas. 
Agradecimientos: Esta aportación ha sido posible gracias al Programa I+D con referencia S2015/HUM3317 "Los Conjuntos Patrimoniales como activos turísticos de la Comunidad de Madrid: problemas y oportunidades en perspectiva territorial", financiado por la Dirección General de Universidades e Investigación de la Comunidad de Madrid y el Fondo Social Europeo.

Declaración responsable: Las/os autoras/es declaran que no existe ningún conflicto de interés con relación a la publicación de este artículo. Asimismo, declaran que ambas se han encargado conjuntamente de las tareas de planteamiento de la investigación, redacción de algunas de las partes del manuscrito y reflexión final. Si bien, la principal contribución de cada autora se ha distribuido de la siguiente manera: Claudia Yubero ha elaborado el marco teórico, la cartografía, el análisis de contenido del programa LEADER y el análisis bibliográfico. María García Hernández ha realizado el análisis de contenido de los Planes en Destino y la revisión final del manuscrito. 


\section{Bibliografía}

Albet, A., \& Benach, N. (2012). Doreen Massey. Un sentido global del lugar. Barcelona: Icaria.

Barrado Timón, D. (2014). Mitos y contramitos, utopías y distopías: las representaciones turísticas de lo rural y sus valoraciones satíricas al amparo del discurso crítico de las ciencias sociales. Scripta Nova, 18. https://doi.org/10.1344/sn2014.18.15065

Beas Secall, L. (2014). Los Planes de Excelencia Turística en España (1992-2006). Una apuesta por la revitalización de los destinos. Revisión de su implementación e impactos. Scripta Nova, 69(59), 1-16. http://dx.doi.org/10.1344/sn2012.16.14772

Benson, D., \& Jordan, A. (2011). What Have We Learned from Policy Transfer Research? Dolowitz and Marsh Revisited. Political Studies Review, 9(3), 366-378. https://doi.org/10.1111/j.1478$\underline{9302.2011 .00240 . x}$

Blancas, J., Guerrero Casas, F. M., \& Lozano Oyola, M. (2009). La localización espacial en la planificación del turismo rural en Andalucía: un enfoque multicriterio. Revista de Estudios Regionales, 7585(84), 83-113. Retrieved from

https: / / www.redalyc.org/articulo.oa? id $=75511780003$

Blanco Herranz, F. J. (1996). Fundamentos de la política comunitaria y española en materia de turismo rural: consideraciones sobre la legislación española. Estudios Turísticos, 131, 25-49. Retrieved from http://www.iet.tourspain.es:20000/img-iet/Revistas/RET-131-1996-pag25-4976831.pdf

Bok, R., \& Coe, N. M. (2017). Geographies of Policy Knowledge: The State and Corporate Dimensions of Contemporary Policy Mobilities. Cities, 63, 51-57. https://doi.org/10.1016/j.cities.2017.01.001

Bomberg, E., \& Peterson, J. (2000). Policy Transfer and Europeanization: Passing the Heineken Test. Qween's Parpers on Europeanisation, 2, 25-43. Retrieved from https://www.researchgate.net/publication/228770062_Queen\%27s_Papers_on_Europeanization _No_22000_Policy_Transfer_and_Europeanization_Passing_the_Heineken_Test

Bonfiglio, A., Camaioni, B., Coderoni, S., Esposti, R., Pagliacci, F., \& Sotte, F. (2017). Are Rural Regions Prioritizing Knowledge Transfer and Innovation? Evidence from Rural Development Policy Expenditure across the EU Space. Journal of Rural Studies, 53, 78-87. https://doi.org/10.1016/j.jrurstud.2017.05.005

Brenner, N., Peck, J., \& Theodore, N. (2010). Variegated Neoliberalization: Geographies, Modalities, Pathways. Global Networks, 10, 1-41.

https://doi.org/https://doi.org/10.1111/j.1471-0374.2009.00277.x. 
Brunet, P. J., Almeida, F., Coll, M., \& Monteserín, O. (2005). Los planes de excelencia y dinamización turística (PEDT), un instrumento de cooperación a favor del desarrollo turístico. Boletín de Asociación de Geógrafos Españoles, 39, 201-226. Retrieved from https://www.agegeografia.es/ojs/index.php/bage/article/view/504

Bull, B. (1999). Encouraging Tourism Development Through the EU Structural Funds: A Case Study of the Implementation of EU Programmes on Bornholm. International Journal of Tourism Research, 1, $149-165$.

https://doi.org/https://doi.org/10.1002/(SICI)1522-1970(199905/06)1:3<149::AID-

ITR167>3.0.CO;2-S

Bulmer, S., \& Padgett, S. (2005). Policy Transfer in the European Union: An Institutionalist Perspective. British Journal of Political Science, 35(1), 103-126. https://doi.org/10.1017/S0007123405000050

Calle Vaquero, M. de la, \& García Hernández, M. (2016). Políticas locales de turismo en ciudades históricas españolas. Génesis, evolución y situación actual. Pasos: Revista de Turismo y Patrimonio Cultural, 14(3), 691-704. Retrieved from http://www.pasosonline.org/es/articulos/933pasos revista_de turismo_y patrimonio_cultural_vol_14_n3_2016 special_issue public action_and tourism_policy

Cañete, J. A., Navarro, F., \& Cejudo, E. (2018). Territorially Unequal Rural Development: the Cases of the LEADER Initiative and the PRODER Programme in Andalusia (Spain). European Planning Studies, 26(4), 726-744. https://doi.org/10.1080/09654313.2018.1424118

Cànoves, G., Garay, L., \& Duro, J. A. (2012). Turismo rural en España: Avances y retrocesos en los últimos veinte años. Papers de Turisme, 51, 7-21. Retrieved from http://www.papersdeturisme.gva.es/ojs/index.php/Papers/article/view/194

Cànoves, G., Villarino, M., \& Herrera, L. (2006). Políticas públicas, turismo rural y sostenibilidad: difícil equilibrio. Boletín de La Asociación de Geógrafos Españoles, 41, 199-217. Retrieved from https://www.age-geografia.es/ojs/index.php/bage/article/view/1997/0

Cheshire, L., Esparcia, J., \& Shucksmith, M. (2015). Community Resilience, Social Capital and Territorial Governance. Ager, 18, 7-38. https://doi.org/10.4422/ager.2015.08

Chevalier, P. (2012). Le transfert du modèle européen LEADER: entre diffusion des normes et durcissement règlementaire. Revue d'études Comparatives Est-Ouest, 43(3), 17-57.

Chevalier, P. (2014). Action locale et développement rural en Europe: le modèle européen LEADER 2007. New York: Peter-Lang. 
Clarke, J., Bainton, D., Lendvai, N., \& Stubbs, P. (2015). Making Policy Move: Towards a Politics of Translation and Assemblage. Bristol (UK): Policy Press.

Comisión de las Comunidades Europeas. (1988). El futuro del mundo rural. Comunicación de la Comisión transmitida al Consejo y al Parlamento Europeo. (Boletín Suplemento No. 4/88). Luxemburgo: Oficina de Publicaciones Oficiales de las Comunidades Europeas.

Consejo Europeo. (2006). Decisión del Consejo de 20 de febrero de 2006 sobre las directrices estratégicas comunitarias de desarollo rural (periodo de programación 2007-2013). In Diario Oficial de la Unión Europea. Retrieved from https://eur-lex.europa.eu/legalcontent/ES/TXT/?uri=LEGISSUM\%3AI60042

Cook, I. (2008). Mobilising Urban Policies: the Policy Transfer of US Business Improvement Districts to England and Wales. Urban Studies, 45(4), 773-795. https://doi.org/hhttp://doi/10.1177/0042098007088468

Cook, I., \& Ward, K. (2011). Trans-urban Networks of Learning, Mega Events and Policy Tourism: The Case of Manchester's Commonwealth and Olympic Games Projects. Urban Studies, 48(12), 2519-2535. https://doi.org/10.1177/0042098011411941

Dax, T., Strahl, W., Kirwan, J., \& Maye, D. (2016). The Leader Programme 2007-2013: Enabling or Disabling Social Innovation and Neo-Endogenous Development? Insights from Austria and Ireland. European Urban and Regional Studies, 23(1), 56-68. https://doi.org/10.1177/0969776413490425

Delgado Viñas, C. (2007). Breve historia crítica y análisis comparativo de las políticas aplicadas en Europa a las áreas de montaña. Investigaciones Geográficas, 42, 35-59. Retrieved from https: / / www.redalyc.org/articulo.oa?id=17612759001

Delpeuch, T. (2008). L'analyse des transferts internationaux de politiques publiques: un état de I'art. Questions de Recherche, 27, 2-69. Retrieved from http://www.ceri-sciencespo.org/publica/qdr.htm

Delpeuch, T. (2009). Comprendre la circulation internationale des solutions d'action publique: panorama des policy transfer studies. Critique Internationale, 43(2), 153-165. https://doi.org/10.3917/crii.043.0153

Directorate-General for Agriculture. (2011). Guía de la DG AGRI para la aplicación del eje LEADER de los Programas de Desarrollo Rural 2007-2013 financiados por el FEADER. Retrieved from https://enrd.ec.europa.eu/sites/enrd/files/fms/pdf/695FAA38-A3CF-93F7-4E94-

E27C74393AA6.pdf 
Dolowitz, D., \& Marsh, D. (1996). Who Learns What from Whom. Political Studies, XLIV, 343357. https://doi.org/10.1111/j.1467-9248.1996.tb00334.x

Dolowitz, D., \& Marsh, D. (2000). Learning from Abroad: The Role of Policy Transfer in Contemporary Policy-Making. Governance, 13(1), 5. https://doi.org/10.1111/0952-1895.00121

Dolowitz, D. P., \& Marsh, D. (2012). The Future of Policy Transfer Research. Political Studies Review, 10(3), 339-345. https://doi.org/10.1111/j.1478-9302.2012.00274.x

Domingo, J., Martínez, S., \& Araque, E. (2012). El turismo en el Parque Natural de las Sierras de Cazorla, Segura y Las Villas: signos de agotamiento y planes de recualificacion. Revista de Turismo y Patrimonio Cultural, 10, 31-45.

Dunlop, C. A. (2017). Policy Learning and Policy Failure: Definitions, Dimensions and Intersections. Policy and Politics, 45(1), 3-18. https://doi.org/10.1332/030557316X14824871742750

Dussauge-Laguna, M. I. (2013). Policy Transfer as a "Contested" Process. International Journal of Public Administration, 36(10). https://doi.org/10.1080/01900692.2013.791312

Ellison, N. (2017). Politics, Power and Policy Transfer. Journal of Asian Public Policy, 10(1), 8-24. https://doi.org/10.1080/17516234.2016.1258519

Esparcia, J. (2014). Innovation and Networks in Rural Areas. An analysis from European Innovative Projects. Journal of Rural Studies, 34(1), 1-14. https://doi.org/10.1016/j.jrurstud.2013.12.004

Esparcia, J., Escribano, J., \& Serrano, J. J. (2015). From Development to Power Relations and Territorial Governance: Increasing the Leadership Role of LEADER Local Action Groups in Spain. Journal of Rural Studies, 42, 29-42. https://doi.org/10.1016/j.jrurstud.2015.09.005

Esparcia Pérez, J., Noguera Tur, J., \& Pitarch Garrido, M. D. (2000). LEADER en Espana: Desarrollo rural, poder, legitimación, aprendizaje y nuevas estructuras. Documents d'Analisi Geografica, (37), 95-113.

European Court of Auditors. (2010). Implementation of the LEADER Approach for rural development. Special Report No 5. Luxembourg. https://doi.org/10.2865/27311

European Union. (1996). La Déclaration de Cork. Retrieved from http://ec.europa.eu/agriculture/rur/leader2/dossier_p/fr/dossier/cork.pdf

European Union. (2016). Cork 2.0 Declaration 2016 A Better Life in Rural Areas. Luxembourg. https://doi.org/10.2762/370418

Evans, M. (2004). Policy Transfer in Global Perspective. London: Ashgate Publishing. 
Foronda, C., \& García, A. M. (2009). La apuesta por la calidad como elemento diferenciador en los destinos turísticos: Planes renovados. Cuadernos de Turismo, (23), 89-110. Retrieved from http://revistas.um.es/turismo/article/view/70191

Freshwater, D., \& Trapasso, R. (2014). The Disconnect Between Principles and Practice: Rural Policy Reviews of OECD Countries. Growth and Change, 45(4), 477-498. https://doi.org/https://doi.org/10.1111/grow.12059

Galdeano-Gómez, E., Aznar-Sánchez, J. A., \& Pérez-Mesa, J. C. (2011). The Complexity of Theories on Rural Development in Europe: An Analysis of the Paradigmatic Case of Almería (Southeast Spain). Sociologia Ruralis, 51(1), 54-78. https://doi.org/10.1111/j.14679523.2010.00524.x

García Marín, R. (2011). Turismo y desarrollo rural en la comarca del Noroeste de la Región de Murcia: los programas europeos LEADER. Cuadernos de Turismo, O(27), 419-435.

Gonzalez, S. (2011). Bilbao and Barcelona "in Motion". How Urban Regeneration "Models" Travel and Mutate in the Global Flows of Policy Tourism. Urban Studies, 48(7), 1397-1418. https://doi.org/10.1177/0042098010374510

Haas, P. (2015). Epistemic Communities, Constructivism, and International Environmental Politics. London: Routledge.

Hadjinski, M., Pal, L., \& Walker, C. (2017). Public Policy Transfer: Micro-Dynamics and MacroEffects. Cheltenham: Edward Elgar.

Hernández Hernández, M. (2008). Balance de las políticas de desarrollo rural en la Comunidad Valenciana (1991-2006). Investigaciones Geográficas, 45, 93-119. https://doi.org/https://doi.org/10.14198/INGEO2008.45.04

Holzinger, K., \& Knill, C. (2005). Causes and Conditions of Cross-National Policy Convergence. Journal of European Public Policy, 12(5), 775-796.

https://doi.org/10.1080/13501760500161357

Ivars Baidal, J. A. (2000). Turismo y espacios rurales: Conceptos, Filosofías y realidades. Investigaciones Geográficas, 20, 59-88. https://doi.org/10.1109/TBC.2011.2160106

Ivars Baidal, J. A. (2004). Tourism Planning in Spain: Evolution and Perspectives. Annals of Tourism Research, 31(2), 313-333. https://doi.org/10.1016/j.annals.2003.12.001

Jajamovich, G. P. (2016). Miradas relacionales sobre la circulación de políticas urbanas: la Corporación Antiguo Puerto Madero y el proyecto ' Mendoza - Madero ' ( 2003-2009 )., 15(3), 67-85. Retrieved from https://digitalcommons.Isu.edu/jlag/vol15/iss3/5/ 
Kovách, I., \& Kučerová, E. (2006). The Project Class in Central Europe: The Czech and Hungarian Cases. Sociologia Ruralis, 46(1), 3-21. https://doi.org/10.1111/j.1467-9523.2006.00403.x

Lacquement, G., \& Chevalier, P. (2016). Capital territorial et développement des territoires locaux, enjeux théoriques et méthodologiques de la transposition d'un concept de l'économieterritoriale à l'analyse géographique. Annales de Geographie, 2016(711), 490-518. https://doi.org/10.3917/ag.711.0490

Lovell, H. (2017). Policy Failure Mobilities. Progress in Human Geography. https://doi.org/10.1177/0309132517734074

Martín, F., \& Martín, I. (2014). Los espacios rurales españoles: ¿territorios donde se produce y consume turismo o destinos sostenibles en entornos competitivos? El caso del nordeste segoviano. Boletín de la Asociación de Geógrafos Españoles, 64, 201-226. http://dx.doi.org/10.21138/bage. 1690

Masot, A. N., \& Alonso, G. C. (2017). 25 years of European Policy in Extremadura: Rural Tourism and LEADER Method. Cuadernos de Turismo, 10071(39), 389-416. http://dx.doi.org/10.6018/turismo.39.290621

McAreavey, R., \& McDonagh, J. (2011). Sustainable Rural Tourism: Lessons for Rural Development. Sociologia Ruralis, 51(2), 175-194. https://doi.org/10.1111/j.1467-9523.2010.00529.x

McCann, E., \& Ward, K. (2010). Relationality / Territoriality: Toward a Conceptualization of Cities in the World. Geoforum, 41(2), 175-184. https:// doi.org/10.1016/j.geoforum.2009.06.006

McCann, E., \& Ward, K. (2011). Mobile Urbanism: Cities \& Policy-Making in the Global Age. Minneapolis: University of Minnesota Press.

McCann, E., \& Ward, K. (2012). Policy Assemblages, Mobilities and Mutations: Toward a Multidisciplinary Conversation. Political Studies Review, 10(3), 325-332. https://doi.org/10.1111/j.1478-9302.2012.00276.x

McCann, E., \& Ward, K. (2013). A Multi-Disciplinary Approach to Policy Transfer Research: Geographies, Assemblages, Mobilities and Mutations. Policy Studies, 34(1), 2-18. https://doi.org/10.1080/01442872.2012.748563

Navarro, F. A., Woods, M., \& Cejudo, E. (2016). The LEADER Initiative has been a Victim of Its Own Success. The Decline of the Bottom-Up Approach in Rural Development Programmes. The Cases of Wales and Andalusia. Sociologia Ruralis, 56(2), 270-288. https://doi.org/10.1111/soru. 12079 
Nemes, G. (2005a). Integrated Rural Development. The Concept and its Operation. (Vol. 6). Budapest: Institute ofEconomics Hungarian Academy of Sciences. Retrieved from http://www.policy.hu/nemes/publikaciok/muhelytaulmany2005_6.pdf

Nemes, G. (2005b). The Politics of Rural Development in Europe (Vol. 5). Budapest: Institute of Economics Hungarian Academy of Sciences. Retrieved from hitp://econ.core.hu/doc/dp/dp/mtdp0505.pdf

Nieto, A., \& Cárdenas, G. (2015). El método LEADER como política de desarrollo rural en Extremadura en los ultimos 20 años (1991-2013). Boletín de La A.G.E., (69), 139-162. https://doi.org/10.21138/bage. 1893

Nieto Masot, A., \& Cárdenas Alonso, G. (2017). Análisis del Método Leader (2007-2013) en Extremadura mediante técnicas SIG y Análisis Multivariado. Cuadernos Geográficos, 56(1), $148-$ 171. Retrieved from http://revistaseug.ugr.es/index.php/cuadgeo/article/view/4015

Nieto Masot, A., \& Cárdenas Alonso, G. (2018). The Rural Development Policy in Extremadura (SW Spain): Spatial Location Analysis of Leader Projects. ISPRS International Journal of GeoInformation, 7(2), 76. https://doi.org/10.3390/ijgi7020076

Oliveira, O. P. De. (2018). Novas fronteiras e direções na pesquisa sobre transferência, difusão e circulação de políticas públicas: agentes, espaços, resistência e traduções. Revista de Administraçao Pública, 52(2), 199-220. http://dx.doi.org/10.1590/0034-761220180078

Osti, G. (2015). LEADER LAGs: Neocorporatist Local Regimes or Examples of Economic Democracy? In L. Granberg, K. Andersson, \&I. Kovách (Eds.), Evaluating the European Approach to Rural Development (pp. 149-164). Surrey: Ashgate Publishing.

Panyik, E., Costa, C., \& Rátz, T. (2011). Implementing Integrated Rural Tourism: An Event-Based Approach. Tourism Management, 32(6), 1352-1363.

https://doi.org/10.1016/j.tourman.2011.01.009

Paül, V. (2013). Hopes for the Countryside'S Future. an Analysis of Two Endogenous Development Experiences in South-Eastern Galicia. Journal of Urban and Regional Analysis, 2, 169-192. Retrieved from

https://www.researchgate.net/publication/270873773_Hopes_for_the_Countryside's_Future_An_ Analysis of Two Endogenous_Development_Experiences_in_South-Eastern_Galicia

Paül, V., Lazovski, O., \& Lois, R. C. (2016). Más de veinte años de LEADER en Galicia: un análisis de su desarrollo en A Limia y A Baixa Limia. In A. R. Ruiz Pulpón, S. de la C.-S. Olmo, \& J. Plaza tabasco (Eds.), Treinta años de políitica agraria común en España (pp. 413-428). Ciudad Real: Asociación de Geórgafos Españoles. 
Peck, J. (2011). Geographies of Policy: From Transfer-Diffusion to Mobility-Mutation. Progress in Human Geography, 35(6), 773-797. https://doi.org/10.1177/0309132510394010

Peck, J., \& Theodore, N. (2010). Mobilizing policy: Models, methods, and mutations. Geoforum, 41(2), 169-174. https://doi.org/10.1016/j.geoforum.2010.01.002

Pitarch, M. D., \& Amandís, R. (2014). Impacto en el sector turístico de las políticas de desarrollo rural en la Comunidad Valenciana Análisis de las estrategias de fomento y revitalización del turismo rural. Documents d'Analisi Geogràfica, 60(2), 315-348. hittps://doi.org/10.5565/rev/dag.52

Ponzinia, D., Fotev, S., \& Mavaracchio, F. (2016). Place Making or Place Faking? The Paradoxical Effects of Transnational Circulation of Architectural and Urban Development Projects. In A. P. Russo \& G. Richards (Eds.), Reinventing the local in tourism. (pp. 153-170). Bristol: Channel View Publications.

Prats, L. (2011). La viabilidad turística del patrimonio. PASOS. Revista de Turismo y Patrimonio Cultura, 9(2), 249-264. https://doi.org/ISSN 1695-7121

Radaelli, C. (2003). The Europeanization of Public Policy. In K. Featherstone \& C. Radaelli (Eds.), The Politics of Europeanization (pp. 27-56). Oxford: Oxford University Press.

Ray, C. (1997). Towards a Theory of the Dialectic of Local Rural Development within the European Union, 37(3). https://doi.org/10.1111/j.1467-9523.1997.tb00055.x

Ray, C. (1999). Towards a Meta-Framework of Endogenous Development: Repertories, Paths, Democracy and Rights. Sociologia Ruralis, 30(4), 521-537. https://doi.org/http://10.1111/1467-9523.00122

Ray, C. (2000). The EU LEADER Programme: Rural Development Laboratory. Sociologia Ruralis, 40(2), 163-171. https://doi.org/10.1111/1467-9523.00138

Ray, C. (2001a). Culture Economies: a Perspective on Local Rural Development in Europe. Newcastle: Centre for Rural Economy.

Ray, C. (2001b). Transnational Co-operation Between Rural Areas: Elements of a Political Economy of EU rural Development. Sociologia Ruralis, 41(3), 279-295. https://doi.org/10.1111/1467$\underline{9523.00183}$

Red Rural Nacional (2011). LEADER en España (1991-2011): una contribución activa al desarrollo rural. Madrid: Ministerio de Medio Ambiente y Medio Rural y Marino.

Rosell, J., \& Viladomiu, L. (2012). Gobiernos locales y política de desarrollo rural en España. Perspectivas Rurales, 17(21), 25-37. Retrieved from https://www. perspectivasrurales.org/index.php/13-ediciones/perspectivas-rurales-21/27gobiernos-locales-politica-desarrollo-rural-espana 
Sánchez, J. M., Sánchez, M., \& Rengifo, J. I. (2017). Análisis del equilibrio entre el potencial turístico y la oferta de alojamientos en turismo rural mediante técnicas de estadística espacial. Cuadernos de Tursmo, 39, 547-576. https://doi.org/10.6018/turismo.39.290701

Saurugger, S., \& Surel, Y. (2006). L'européanisation comme processus de transfert de politique publique. Revue Internationale de Politique Comparée, 13(2), 179-211. https://doi.org/10.3917/ripc. 132.0179

Scott, A. J., Shorten, J., Owen, R., \& Owen, I. (2011). What Kind of Countryside do the Public Want: Community Visions from Wales UK. Geojournal, 76(4), 417-436. https://doi.org/10.1007/s10708-009-9256-y

Secretaría General de Turismo. (1992). Plan Marco de competitividad del turismo español: 19921996. Madrid: Ministerio de Industria, Comercio y Turismo.

Secretaría General de Turismo. (2000). Plan Integral de Calidad del Turismo Español 2000_ 2006. Madrid: Ministerio de Economía y Hacienda.

Sharpley, R., \& Roberts, L. (2004). Rural Tourism - 10 years on. International Journal of Tourism Research, 6(3), 119-124. https://doi.org/10.1002/jtr.478

Smith, A. (1996). Europe politique au miroir du local. Les fond structurels et les zones rurales en France et en Espagne. Paris: L'Harmattan.

Solsona, J., \& López, D. (2012). Factores de localización y desarrollo turístico en el espacio rural de la Comunitat Valenciana. Boletín de La Asociación de Geógrafos Españoles, 59, 221-244. Retrieved from http://www.age-geografia.es/ojs/index.php/bage/article/viewFile/1456/1377

Stead, D., de Jong, M., \& Reinholde, I. (2008). Urban Transport Policy Transfer in Central and Eastern Europe. The Planning Review, 44(172), 62-73. https://doi.org/10.1080/02513625.2008.10557003

Stone, D. (1999). Learning Lessons and Transferring Policy across Time, Space and Disciplines. Politics, 19(1), 51-59. https://doi.org/10.1111/1467-9256.00086

Stone, D. (2004). Transfer Agents and Global Networks in the "Transnationalization" of Policy. Journal of European Public Policy, 17(3), 545-566. https://doi.org/10.1080/13501760410001694291

Stone, D. (2012). Transfer and Translation of Policy. Policy Studies, 33(6), 483-499. https://doi.org/10.1080/01442872.2012.695933

Stone, D. (2017). Understanding the Transfer of Policy Failure: Bricolage, Experimentalism and Translation. Policy and Politics, 45(1), https://doi.org/10.1332/030557316X14748914098041 
Temenos, C., \& McCann, E. (2012). The Local Politics of Policy Mobility: Learning, Persuasion, and the Production of a Municipal Sustainability Fix. Environment and Planning A, 44(6), 1389-1406. https://doi.org/10.1068/a44314

Temenos, C., \& McCann, E. (2013). Geographies of Policy Mobilities. Geography Compass, 7(5), 344-357. https://doi.org/10.1111/gec3.12063

Tirado Ballesteros, J. G., \& Hernández Hernández, M. (2017). Assessing the Impact of EU Rural Development Programs on Tourism. Tourism Planning and Development, 14(2), 149-166. https://doi.org/10.1080/21568316.2016.1192059

Tirado Ballesteros, J. G., \& Hernández, M. H. (2018). Promoting Tourism through the EU LEADER Programme: Understanding Local Action Group Governance. European Planning Studies, 27(2), 1-19. https://doi.org/10.1080/09654313.2018.1547368

Valenzuela, M., García, A. J. P., \& Giralt, H. (2008). La valorización turística del patrimonio minero en entornos desfavorecidos. Actores y experiencias. Cuadernos de Turismo, 22, 231-260. Retrieved from https://revistas.um.es/turismo/article/view/48201

Van Der Ploeg, J. D., Renting, H., Brunori, G., Knickel, K., Mannion, J., Marsden, T., ... Ventura, F. (2000). Rural Development: From Practices and Policies towards Theory. Sociologia Ruralis, 40(4). https://doi.org/10.1111/1467-9523.00156

Vázquez-Barquero, A., \& Rodríguez-Cohard, J. C. (2016). Endogenous Development and Institutions: Challenges for Local Development Initiatives. Environment and Planning C: Government and Policy, 34(6), 1135-1153. https://doi.org/10.1177/0263774X15624924

Vázquez Varela, C., \& Martín Gil, F. (2011). Problemas de sostenibilidad del turismo rural en España. Anales de Geografía, 31(1), 171-194. https://doi.org/10.5209/rev

Velasco González, M. (2004). Administración y política turística de 1978 a 2005. Estudios Turí Sticos, 164(163-164), 99-122. Retrieved from http://www.iet.tourspain.es/img-iet/Revistas/RET163-164-2005-pag99-122-92461.pdf

Yubero, C. (2017). Développement local et transfert de modèle: apprentissage d'une norme et reconstruction géographique? In K. Kadir, M. Niang, \& A. Trousselle (Eds.), Les sentiers du développement, de l'art à la manière. Montpellier: Presses Universitaires de la Méditerrannée.

Zasada, I., \& Piorr, A. (2015). The Role of Local Framework Conditions for the Adoption of Rural Development Policy: An Example of Diversification, Tourism Development and Village Renewal in Brandenburg, Germany. Ecological Indicators, 59, https://doi.org/10.1016/j.ecolind.2015.02.002 